\title{
Comparative evaluation of anesthetic efficacy of $2 \%$ lidocaine and $4 \%$ articaine in irreversible pulpitis cases during endodontic therapy - a randomized double blind study
}

\author{
Buggaveeti Pradeep Kumar ${ }^{*}$, K.Sirisha ${ }^{2}$, M. Jyothi ${ }^{3}$, S.Anitha Rao ${ }^{4}$ \\ ${ }^{1}$ Senior Lecturer, ${ }^{2}$ Professor, ${ }^{3,4}$ Professor and HOD, Dept. of Conservative Dentistry and Endodontics, ${ }^{1,4}$ Mamata Dental College, \\ Khammam, Telangana, ${ }^{2,3}$ GITAM Dental College and Hospital, Visakhapatnam, Andhra Pradesh, India
}

*Corresponding Author: Buggaveeti Pradeep Kumar

Email: pradeepbuggaveeti@gmail.com

\begin{abstract}
Introduction: Profound local anesthesia in permanent mandibular molars in irreversible pulpitis cases is difficult to attain with inferior alveolar nerve block (IANB) alone. In many cases, supplemental anesthesia is required during root canal therapy. The objectives of the present study are to compare the effectiveness of 2\% Lidocaine and 4\% Articaine when used for inferior alveolar nerve block (IANB) and supplemental buccal infiltration (BI) in irreversible pulpitis cases.

Materials and Methods: Twenty five patients were randomly alloted to control and test groups. Test group included thirteen patients, anesthetized with 4\% Articaine (with 1:100,000 epinephrine) and twelve patients were anesthetized with 2\% Lidocaine (with 1:80,000 epinephrine) in control group. The pain experienced by patients during treatment was analyzed by using Heft-Parker visual analogue scale (HP-VAS). In case of pain after IANB, a supplemental buccal infiltration was given with the same anesthetic that was used for IANB. Absence of pain or presence of mild pain was considered as anesthetic success and presence of moderate or severe pain was considered as anesthetic failure. The data was recorded and evaluated using Chi-square test and proportion test. The level of significance was set at 0.05 .

Results: After inferior alveolar nerve block, anesthetic success was 54\% in Articaine (test) group and 17\% in Lidocaine (control) group.Following buccal infiltration, it was $83 \%$ in Articaine group and $70 \%$ in Lidocaine group. There was no significant difference between two groups after IANB and buccal infiltration. Overall success of Articaine was 92\% and Lidocaine was $75 \%$.

Conclusion: There was no significant difference in the proportions of the overall success rate between the two groups. Articaine $4 \%$ can be considered as a useful alternative for $2 \%$ Lidocaine in teeth with irreversible pulpitis cases during root canal therapy.
\end{abstract}

Keywords: Articaine, Lidocaine, Inferior alveolar nerve block, Buccal infiltration, Heft-Parker visual analogue scale, Irreversible pulpitis.

\section{Introduction}

The management of pain in endodontics represents a challenge for the endodontist due to pharmacological factors (e.g., reduced anesthetic success), behavioral factors (e.g., patient apprehension), and practice management (e.g.relationship with referring practitioner) issues. ${ }^{1}$

Pain management can be accomplished by blocking nociceptive impulses along the peripheral nerves, reducing nociceptive input from the site of injury and preventing pain perception in the central nervous system. Blocking the sensitive impulses during root canal treatment is performed with the administration of local anesthesia. ${ }^{2}$

Local anesthetics are most commonly used for pain control techniques in dentistry. Hence a thorough knowledge of local anesthetic solutions and proper use of local anesthesia techniques are essential for pain-free dental treatment. Problems arising in achieving profound pulpal anesthesia invariably develop in the mandible with less frequency in maxillary teeth. ${ }^{3}$

Anesthesia for permanent mandibular teeth is usually obtained by inferior alveolar nerve block (IANB). ${ }^{4}$ It provides at least one hour of pulpal anesthesia in about $85 \%$ of the cases when local anesthetics with intermediate duration and equivalent potency associated with a vasoconstrictor are used.However, success of pulpal anesthesia is not guaranteed and may be compromised by many other factors. ${ }^{5}$ Clinical studies in endodontics have found failure with the IANB occurring between $44 \%$ and $81 \%$ of the time. ${ }^{6}$ The reasons for failure of local anesthetics including anatomic variations like cross innervations and accessory innervations, reduced local $\mathrm{pH}$, tachyphylaxis of anesthetic solutions, and activation of nociceptors including tetrodotoxin and capsaicin-sensitive transient receptor potential vanilloid type 1 . A number of other methods like infiltration anesthesia may be useful in overcoming collateral supply.

Lignocaine hydrochloride was most commonly used local anesthetic agent. It was labeled as "Gold Standard" to which other local anesthetics can be compared. ${ }^{7}$ Failures were reported when Lignocaine was used for inferior alveolar nerve block. ${ }^{8}$

Articaine have been evaluated by many researchers in endodontics for its efficacy and safety. ${ }^{9}$ Few studies reported improved success with Articaine whereas others reported absence of significant difference.

The study was done to compare the efficacy of $2 \%$ Lidocaine and 4\% Articaine after IANB and buccal infiltration in permanent mandibular first molars diagnosed with irreversible pulpitis.

\section{Materials and Methodology}

Research protocol was endorsed by research committee of NTR University of Health Sciences. Ethical clearance was prevailed from ethical committee of Gitam Dental College and Hospital, Vizag. Patients with a chief complaint of decayed mandibular posterior teeth having mild to severe pain were selected for the study. Gender was not taken into consideration. Patient's chief complaint, history of pain (location, duration, nature, quality and frequency), past dental history and present systemic health status (cardiac 
illness, diabetes mellitus, epileptic seizures, allergic reactions to medicines and pregnancy) were recorded.

After thorough clinical examination of the involved tooth, pulp sensitivity was evaluated by thermal tests (with endo frost (Coltenewhaledent, Langenau, Germany) and heated gutta-percha sticks) and electric pulp test (Digitest, ParkellInc, Edgewood, Newyork, USA). Radiological examination of the involved tooth was done to assess the periradicular status and anatomical aberrations. The final diagnosis of irreversible pulpitis was corroborated on the basis of history, clinical and radiological presentation.

\section{Inclusion criteria}

1. Patients within the age group of $15-55$ years.

2. Permanent mandibular teeth with irreversible pulpitis.

3. Pulpally involved teeth with positive response to electric pulp test, positive and lingering response to thermal tests.

4. Patients with good systemic health.

5. Patients who were willing to participate in the study by understanding the pain scale.

\section{Exclusion criteria}

1. Permanent mandibular teeth with clinical diagnosis of pulp necrosis with periapical pathology.

2. Permanent mandibular teeth with periapical radiolucency on intra oral periapical radiograph (except for periodontal ligament widening).

3. Patients who had taken pain modifiers within last twelve hours.

4. Patients with known allergy and sensitivity to any of the components of local anesthetic solutions.

5. Patients who require prophylactic antibiotic therapy or tricyclic antidepressants due to systemic complications.

6. Pregnant and lactating women.

7. Patients with intraoral lesions at the injection site.

Thirty two subjects were enrolled and randomly assigned to control and test groups. Six subjects were excluded; five subjects due to the use of pain modifiers, one subject due to cardiac disease.

After selection of the patient, a consent form that was filled and signed by the patient was collected. Twenty six patients (both men and women) between the age group of 15 to 55 years were selected for this double blind randomized clinical study. Prior to local anesthesia administration pretreatment pain intensity was analyzed using Heft-Parker visual analogue scale (HP-VAS). (Fig. 1)

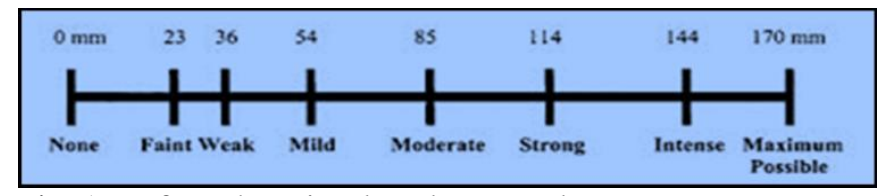

Fig. 1: Heft-Parker visual analogue scale

The patients were randomly divided into two groups ( $\mathrm{n}=13$ each) i.e. Lidocaine group (control) and Articaine group (test). Equivalent number of Lidocaine and Articaine cartridges are available and the Senior Assistant in the department was aware of the codes and gave out the cartridges randomly in equal numbers according to the groups of Lidocaine or Articaine.One particular code was given for each of the two cartridges and packed together because the block and infiltration injections were supposed to be administered by using the same anesthetic. Thus the operator also was not aware of the anesthetic that was used. All patients received $1.8 \mathrm{ml}$ of inferior alveolar nerve block (IANB) with 2\% Lidocaine; 1:80,000 Epinephrine or 4\% Articaine with 1:100,000 Epinephrine.

Fifteen minutes after local anesthetic administration, Patients without lip numbness were excluded from the study, and their cartridges were replaced. Thus one patient was eliminated due to absence of lip numbness.

After evaluating the subjective symptoms of profound anesthesia, isolation was done using rubber dam and access cavity was prepared with high speed air rotor hand piece using Endo access diamond stone (Dentsply/Maillefer, Tulsa, Okla), \#4 round carbide bur (MANI, INC. Tochigi, Japan), and Endo Z bur (Dentsply/Maillefer, Tulsa, Okla). Access cavity preparation procedure was standardized by using a new set of burs for each patient.

After the "drop in" into the pulp chamber was obtained, the bur was moved laterally and occlusally, finishing of access cavities was done with Endo $\mathrm{Z}$ carbide fissure burs to finish and slope the walls of the access cavity. The pulp chamber was irrigated with $3 \%$ sodium hypochlorite ( $\mathrm{NaOCl})$ (VISHAL Limited, Ahmadabad, Gujarat, India) followed by saline (Parenteral Surgical Limited, Indore, India) and root canal orifices were explored with endodontic explorer (DG-16, Dentsply/Maillefer, Switzerland).

Patients were instructed to lift their hand if any pain was obtained throughout the procedure. In case of pain during the treatment, the procedure was stopped and patients were asked to mark the pain on the Heft-Parker visual analogue scale throughout the various stages of the treatment..

Patients who had moderate-to-severe pain, the rubber dam was removed, and the buccal infiltration was administered with the same anesthetic solution that was used for performing inferior alveolar nerve block. After five minutes, root canal therapy was continued. In patients who had moderate-to-severe pain based on the HP-VAS, the buccal infiltration was considered as failure. In those conditions, either intrapulpal or intraligamentary technique was employed to complete the endodontic therapy. All the pain scale data was recorded, tabulated and subjected for statistical analysis. After endodontic therapy access cavity was restored with intermediate restorative material (IRM).

\section{Results}

Data was recorded and evaluated using SPSS (Statistical Package for the Social Sciences) version 16 and mini tab version 16. Chi-square test and proportion test were used to test hypothesis and the level of significance was set at 0.05 . Success criteria considered was absence of moderate or severe pain. Thus after inferior alveolar nerve block, seven 
patients $(54 \%)$ in articaine group had mild or no pain during the procedure, whereas two patients (17\%) in lidocaine group had only mild or no pain during the procedure (Table 1)

Table 1: Intergroup Comparison of IANB success with Two Local Anesthetics

\begin{tabular}{|c|c|c|c|c|c|c|}
\hline Group & $\mathbf{X}$ & $\mathbf{N}$ & $\mathbf{P}(\mathbf{x} / \mathbf{n})$ & $\mathbf{Z}$ & $\mathbf{p}$-value & Decision \\
\hline $\begin{array}{c}\text { Articaine } \\
\text { (Test) }\end{array}$ & 7 & 13 & 0.5385 & 2.12 & 0.034 & Significant \\
\cline { 1 - 3 } $\begin{array}{c}\text { Lidocaine } \\
\text { (Control) }\end{array}$ & 2 & 12 & 0.1667 & & & \\
\hline
\end{tabular}

It was observed that there was significant difference between the efficacies of two local anesthetics after inferior alveolar nerve bock i.e. both are independent at $5 \%$ level of significance. The success proportion of Articaine group is greater than Lidocaine group.

In the patients who had moderate to severe pain after inferior alveolar nerve block, buccal infiltration was given. After buccal infiltration there was mild or no pain in five patients in Articaine group, and seven patients in Lidocaine group during the procedure. There was no statistically significant difference in the success of buccal infiltration within the two groups (Table 2).

Table 2: Intergroup Comparison of Buccal Infiltration Success with Two Local Anesthetics

\begin{tabular}{|c|c|c|c|c|c|c|}
\hline Group & $\mathbf{X}$ & $\mathbf{N}$ & $\mathbf{P}$ & $\mathbf{Z}$ & $\mathbf{p}$-value & Decision \\
\hline $\begin{array}{c}\text { Articaine } \\
\text { (Test) }\end{array}$ & 5 & 6 & 0.833 & 0.63 & 0.526 & $\begin{array}{c}\text { Not } \\
\text { Significant }\end{array}$ \\
\cline { 1 - 4 } $\begin{array}{c}\text { Lidocaine } \\
\text { (Control) }\end{array}$ & 7 & 10 & 0.7 & & & \\
\hline
\end{tabular}

It was evaluated that Articaine has slightly higher success rate and there was no significant difference between two local anesthetics in the overall success rate during root canal treatment (Table 3).

Table 3: Overall success rate of two groups

\begin{tabular}{|c|c|c|c|c|c|c|}
\hline Group & $\mathbf{X}$ & $\mathbf{N}$ & $\mathbf{P}$ & $\mathbf{Z}$ & $\mathbf{p}$-value & Decision \\
\hline $\begin{array}{c}\text { Articaine } \\
\text { (Test) }\end{array}$ & 12 & 13 & 0.929 & 1.19 & 0.233 & $\begin{array}{c}\text { Not } \\
\text { Significant }\end{array}$ \\
\cline { 1 - 3 } $\begin{array}{c}\text { Lidocaine } \\
\text { (Control) }\end{array}$ & 9 & 12 & 0.75 & & & \\
\hline
\end{tabular}

\section{Discussion}

The primary goal of endodontic therapy is to remove irritants from the pulp canal and obturate the cleaned and shaped root canal system, thus preventing future recontamination of sealed root canals. ${ }^{10}$ Inferior alveolar nerve block was given to anesthetize the mandibular teeth. During the pulpectomy, sharp pain can occur if performed under inadequate anesthesia in patients with irreversible pulpitis. $^{12}$

In patients with inflamed tissue local anesthetics are less effective. ${ }^{13}$ The low tissue $\mathrm{pH}$ results in a greater proportion of the local anesthetic being trapped in the charged acid form of the molecule and therefore, unable to cross cell membranes. Local anesthetics with lower $\mathrm{pKa}$ values are likely to be more effective in patients of pulpalgia. Patients with irreversible pulpitis had an 8-fold higher failure of local anesthetic injections in comparison to normal control patients. ${ }^{14}$

Inflammation also induces changes in the CNS's pain processing system. Activation and sensitization of nociceptors in pulpal and periradicular tissues result in a barrage of impulses sent to the trigeminal nucleus and brain. This barrage, in turn, produces central sensitization. Central sensitization is the increased excitability of central neurons and is thought to be a major cause of hyperalgesia. Under normal conditions, a local anesthesia blocks $90 \%$ of the fibers may be clinically successful. But in conditions of central sensitization, due to exaggerated central nervous system (CNS) response, even 90\% inferior alveolar nerve block may be inadequate to control the pain during root canal treatment.This central sensitization may leads to local anesthetic failure. Unfortunately, there are no selective drugs for blocking central sensitization. ${ }^{11}$

Accessory innervation to the mandibular teeth from various origins has been a cause for inadequate anesthesia. Patient apprehension may leads to local anesthetic failure. Apprehensive patients have a reduced pain threshold and unpleasant dental experience. ${ }^{15}$

Lidocaine is an amide local anesthetic, it's chemical formula is 2-Diethylamino 2',6-acetoxylidide hydrochloride. Its dissociation constant (pKa) is 7.9 and anesthetic half-life is 1.6 hours ( 90 minutes). Its onset of action is rapid ( 2 to 3 minutes). Manufacturer's maximum recommended dose of Lidocaine with Epinephrine is $3.2 \mathrm{mg} / \mathrm{lb}$ or $7.0 \mathrm{mg} / \mathrm{kg}$ of body weight for the adult patient, not to exceed $500 \mathrm{mg} .{ }^{16}$

Articaine hydrochloride is the only local anesthetic of amide type that contains a thiophene group. Its $\mathrm{pKa}$ is 7.8 and anesthetic half-life is 0.5 hours. It's onset of action is 2 to $2 \frac{1}{2}$ minutes for mandibular block and 1 to 2 minutes for infiltration and maximum recommended dose by manufactures is $3.2 \mathrm{mg} / \mathrm{lb}$ or $7.0 \mathrm{mg} / \mathrm{kg}$ of body weight for the adult patient.

Articaine is one of the safer local anesthetic due to its rapid metabolism into an inactive metabolite, decreasing the risk of systemic toxicity and overdose, even after repeated injection. The manufacturer's maximum recommended dose for a healthy $70-\mathrm{kg}$ adult is seven cartridges of an Articaine solution compared with thirteen cartridges of a $2 \%$ Lidocaine solution. ${ }^{16}$ It can be used as 1:100,000 and 1:200,000 epinephrine. ${ }^{17}$

The Heft-Parker visual analogue scale (HP-VAS) was used to assess the pain intensity throughout the therapy. Heft-Parker visual analogue scale is a $170 \mathrm{~mm}$ line. Absence of pain commensurate to $0 \mathrm{~mm}$. Mild pain refers to faint, weak, and mild pain commensurate to greater than 0 $\mathrm{mm}$ up to $54 \mathrm{~mm}$, moderate pain commensurate to greater than $54 \mathrm{~mm}$ up to $114 \mathrm{~mm}$, and severe pain refers to strong, intense, and maximum possible amount of pain commensurate to greater than $114 \mathrm{~mm}$ up to $170 \mathrm{~mm}$. 
Patients were asked to mark their pain on this scale during the root canal treatment procedure. ${ }^{18}$

Lingering painful thermal responses, particularly to cold are the classic form of irreversible pulpitis.Pain is intensified by a stimulus but can be spontaneous. It is typically episodic in nature initially but may progress into a constant intense pain or toothache. ${ }^{12}$

Fifteen minutes after the administration of local anesthesia, the patients were asked about development of lip numbness. Patients without lip numbness were not include in the study, and their cartridges were replaced. ${ }^{19}$ Thus one patient was eliminated from the study due to absence of lip numbness. Lip numbness or tingling indicates anesthesia of the mental nerve, a terminal branch of the inferior alveolar nerve. It is a good indication that the inferior alveolar nerve is anesthetised, although not a reliable indicator for depth of anesthesia. ${ }^{20}$

Endodontic procedure was initiated fifteen minutes after inferior alveolar nerve block. This is based on the findings of Jung YlL et al. ${ }^{21}$ It was observed that an onset time of 10 to 15 minutes is required after injection to attain complete anesthetic effect.

A single operator has administered all local anesthetics to maintain standardization in administration technique. ${ }^{15} \mathrm{~A}$ standard sized new bur (No.4) (BR - 41) (MANI, INC. Tochigi, Japan) was used for each patient as a measure of standardization. Different sizes of burs will have varying areas of contact which results in differences in the amount of heat generation. ${ }^{22}$ To standardize the thermal stimulus, same size of burs were used for preparing access cavity.

It was observed that Articaine success rate $(53 \%)$ was higher than that of Lidocaine (17\%) after nerve block. This might be due to high diffusion of Articaine and slightly lower $\mathrm{pKa}$ than that of Lidocaine. ${ }^{15}$ There was no statistically significant difference in the success rates of Articaine and Lidocaine after IANB according to Claffey E et $\mathrm{al}^{23}$ Tortamano IP et al, ${ }^{24}$ and Poorni $\mathrm{S}$ et al. ${ }^{25}$ In contrary, Ashraf $\mathrm{H}$ et $\mathrm{al}^{19}$ reported higher success rate in Lidocaine group than Articaine group though there was no significant difference.

In cases of moderate or severe pain, buccal infiltration of the same anesthetic agent was given. It is recommended to wait for five minutes after infiltration injection before continuation of endodontic therapy. ${ }^{21}$ After buccal infiltration, Articaine success rate was found to be slightly higher than that of Lidocaine. It may be due to rapid diffusion of Articaine through the buccal cortex to extent upto inferior alveolar nerve. ${ }^{26}$ In the present study there was no statistically significant difference between Lidocaine (70\%) and Articaine (83\%). The results was in accordance to Rosenberg PA et al. ${ }^{27}$ Improved success may be attributed to the effect on accessory innervations and a limited diffusion of Lidocaine through compact cortical bone. In contrary, Ashraf et $\mathrm{al}^{19}$ found that there was significant difference between Articaine and Lidocaine after buccal infiltration $(\mathrm{p}<.001)$. The differences in success rates may be due to potential population differences. ${ }^{28}$
Contradictory studies were reported in the literature regarding the efficacy of Articaine in maxillary teeth with irreversible pulpitis. Srinivasan $\mathrm{N}$ et $\mathrm{al}^{29}$ stated that statistically significant difference between Articaine and Lidocaine, whereas Kanaa MD et $\mathrm{al}^{30}$ found no significant difference.

In the present study $92 \%$ in Articaine group and $75 \%$ in Lidocaine group had no pain during the endodontic procedure after IANB and buccal infiltration. It was stated that even though Articaine has slightly higher success rate, but there was no significant difference between two local anesthetic agents $(\mathrm{p}<0.05)$.

The failure rate may be due to the limited volume of the anesthetic to diffuse through the entire thickness of the mandibular alveolus. In these situations other management options like intrapulpal anesthesia, intraosseous injection, and periodontal ligament injection can be used.

\section{Conclusions}

Within the limitations in the present study, 4\% Articaine ; 1:100,000 epinephrine was more effective than $2 \%$ Lidocaine 1:80,000 epinephrine during inferior alveolar nerve block in producing pulpal anesthesia in mandibular molars with irreversible pulpitis.

After buccal infiltration, there was no statistically significant difference between $4 \%$ Articaine and $2 \%$ Lidocaine.

Overall success rate with $4 \%$ Articaine was $92 \%$ and with $2 \%$ Lidocaine was $75 \%$ after inferior alveolar nerve block and buccal infiltration.

Neither 4\% Articaine nor 2\% Lidocaine could provide complete anesthesia after inferior alveolar nerve block and buccal infiltration.

\section{Source of funding}

None.

\section{Conflcit of interest}

None.

\section{References}

1. Hargreaves KM, Reader AL, Nusstein JM, Marshall JG, Gibbs JL. : Pharmacologic management of endodontic pain, Ingle's Endodontics. Ingle's Endod 2008, 6th edition:713.

2. Parirokh M, Abbott PV: Various strategies for pain-free root canal treatment. Iran Endod J 2014;9:1-14.

3. Walton RE, Abbott BJ: Periodontal ligament injection: a clinical evaluation. J Am Dent Assoc 1981;103:571-5.

4. Aggarwal V, Jain A, Kabi D: Anesthetic efficacy of supplemental buccal and lingual infiltrations of articaine and lidocaine after an inferior alveolar nerve block in patients with irreversible pulpitis. J Endod 2009;35:9259. 10.1016/j.joen.2009.04.012

5. Meechan JG: Why does local anaesthesia not work every time? . Dent Update 2005;32:66-72.

6. Cohen HP, Cha BY, Spangberg LSW: Endodontic anesthesia in mandibular molars: a clinical study. J Endod 1993;19:370-3.

7. Malamed SF: Clinical Action of Specific Agents, Handbook of local anesthesia. 5th ed. St. Louis, CV Mosby. 2004, 63.

8. Kanaa MD, Whitworth JM, Corbett IP, Meechan JG: Articainebuccal infiltration enhances the effectiveness of 
lidocaine inferior alveolar nerve block. Int Endod J 2009;42:238-46.

9. Malamed SF, Gagnon S, Leblanc D: A comparison between articaine $\mathrm{HCl}$ and lidocaineHCl in pediatric dental patients. Pediatr Dent 2000;22:307-11.

10. Stashenko P: Interrelationship of dental pulpal and apical periodontitis. Seltzer and Bender's Dental Pulp, Hargreaves KM, Goodis HE, Quintessence Publishing Co., Inc. 2002, 389:410. https://doi.org/10.1016/0030-4220(63)90385-2

11. Hargreaves KM, Keiser K: Local anesthetic failure in endodontics: mechanisms and management. Endod Topics 20021:26-39.

12. Ingle JI, Bakland LK, Baumgartner JC: Diagnosis of Endodontic Disease, Ingle's Endodontics. 6th ed. B.C. Decker, Inc London. 2008, 528.

13. Walton R, Torabinejad M: Managing local anesthesia problems in the endodontic patient. J Am Dent Assoc 1992;123:97-

102. https://doi.org/10.14219/jada.archive.1992.0133

14. Khan AA, Ren K, Hargreaves KM: Neurochemical Factors in Injury and Inflammation in Orofacial Tissues. In. Lavigne G, Lund J, Sessle B, Dubner R. eds. Orofacial Pain: Basic Sciences to Clinical Management. Chicago: Quintessence. Publishing Co Inc, 2001. 45-52.

15. Wong M, Jacobsen P: Reasons for local anesthesia failures. $J$ Am Dent Assoc 1992;12:69-73. https://doi.org/10.14219/jada.archive.1992.0004

16. Malamed SF: Clinical action of specific agents, Handbook of local anesthesia. 5th ed. St Louis: Mosby. 2004, 62.

17. McEntire M, Nusstein J, Drum M, Reader A, Beck M: Anesthetic efficacy of 4\% articaine with 1: 100,000 epinephrine versus 4\% articaine with 1: 200,000 epinephrine as a primary buccal infiltration in the mandibular first molar. $J$ Endod 2011, 37:450454. https://doi.org/10.1016/j.joen.2010.12.007

18. Heft MW, Parker SR: An experimental basis for revising the graphic rating scale for pain. Pain 1984;19:153-61. https://doi.org/10.1016/0304-3959(84)90835-2

19. Ashraf H, Kazem M, Dianat O, and Noghrehkar F: Efficacy of articaine versus lidocaine in block and infiltration anesthesia administered in teeth with irreversible pulpitis: a prospective, randomized, double-blind study. J Endod 2013;39, 6:10. https://doi.org/10.1016/j.joen.2012.10.012

20. Malamed SF: Techniques of mandibular anesthesia, Hand book of local anesthesia, 5th ed. Elsevier, St. Louis, Missouri; 2004. 233.

21. Jung YlL, Kim JH, Kim SE, Lee CY and Lee SJ: An evaluation of buccal infiltrations and inferior alveolar nerve blocks in pulpal anesthesia for mandibular first molars. $J$ Endod 2008;34:11-3. https://doi.org/10.1016/j.joen.2007.09.006
22. Marzouk M.A., Simonton A.L., Gross R.D: Operative dentistry armamentarium, Operative dentistry Modern Theory and Practice. Ishiyaku Euro Am Inc 1993:69.

23. Claffey E, Reader A, Nusstein J, Beck M, Weaver J.: Anesthetic efficacy of articaine for inferioralveolar nerve blocks in patients with irreversible pulpitis. J Endod 2004;30:568-71.

24. Tortamano IP, Siviero M, Costa CG, Buscariolo IA, Armonia PL: A comparison of the anesthetic efficacy articaine and lidocaine in patients with irreversible pulpitis. $J$ Endod 2009;35:165-8. https://doi.org/10.1016/j.joen.2008.10.020

25. Poorni S, Veniashok B, Senthilkumar AD, Indira R, and Ramachandran S: Anesthetic efficacy of four percent articaine for pulpal anesthesia by using inferior alveolar nerve block and buccal infiltration techniques in patients with irreversible pulpitis: a prospective randomized double-blind clinical trial. $J$ Endod 2011;37:1603-7. https://doi.org/10.1016/j.joen.2011.09.009

26. Whitworth JM, Kanaa MD, Corbett IP, Meechan JG: Influence of injection speed on the effectiveness of incisive/ mental nerve block: a randomized, controlled, double-blind study in adult volunteers. J Endod. 2007, 33:11491154. https://doi.org/10.1016/j.joen.2007.07.016

27. Rosenberg PA, Amin KG, Zibari Y and Lin LM: Comparison of 4\% Articaine with 1: 100,000 Epinephrine and 2\% Lidocaine with 1: 100,000 Epinephrine When Used as a. Supplemental Anesthetic. J Endod 2007;33:403-5. https://doi.org/10.1016/j.joen.2006.11.019

28. Martin M, Nusstein J, Drum M, Reader AL, and Beck M: Anesthetic efficacy of $1.8 \mathrm{ml}$ versus $3.6 \mathrm{ml} 4 \%$ articaine with 1: 100,000 epinephrine as a primary buccal infiltration of mandibular first molar. $J$ Endod 2011;37:588-92. https://doi.org/10.1016/j.joen.2011.01.001

29. Srinivasan N, Kavitha M, Loganathan CS, Padmini G: Comparison of anesthetic efficacy of $4 \%$ articaine and $2 \%$ lidocaine for maxillary buccal infiltration in patients with irreversible pulpitis. Oral Surg Oral Med Oral Pathol Oral Radiol Endod 2009:107:1336. https://doi.org/10.1016/j.tripleo.2008.09.002

30. Kanaa MD, Whitworth JM, Meechan JG: A comparison of the efficacy of 4\% articaine with 1: 100,000 epinephrine and 2\% lidocaine with 1: 80,000 epinephrine in achieving pulpal anesthesia in maxillary teeth with irreversible pulpitis. J Endod 2012;38:279-82. https://doi.org/10.1016/j.joen.2011.11.010

How to cite: Kumar BP, Sirisha K, Jyothi M, Rao SA. Comparative evaluation of anesthetic efficacy of $2 \%$ lidocaine and $4 \%$ articaine in irreversible pulpitis cases during endodontic therapy - a randomized double blind study. Indian J Conserv Endod 2020;5(1):6-10. 